\title{
INFRASTUKTUR TEKNOLOGI INFORMASI YANG MENUNJANG STRATEGI BISNIS PADA PERUSAHAAN TAMBANG: STUDI KASUS PT XYZ
}

\author{
Eli Suryani \\ Information Systems Department, School of Information Systems, Binus University \\ J1. K.H. Syahdan No. 9, Palmerah, Jakarta Barat 11480 \\ esuryani@gmail.com
}

\begin{abstract}
The purposeof this study is to analyze, evaluate and recommend infrastructure of information technology that addresses its flexibility to run along the continouing development of the company, to avoid the potential risk that may come which is more costly for the company due to failure in dealing with those changes. To obtain more accurate data and information, this study uses observation and interview technique with the top management and key person from Information Technology Department. It can be concluded that strengthening the information technology infrastructure is able to strengthen business processes that built upon it, and enhance more value to the company.
\end{abstract}

Keywords: information technology infrastructure, flexibility, business process

\begin{abstract}
ABSTRAK
Tujuan penelitian ini adalah menganalisis, menilai dan merekomendasikan infrastuktur teknologi informasi yang mampu menjawab fleksibilitas perkembangan yang terjadi di dalam perusahaan, untuk menghindari potensi resiko yang besar dan mahal yang perlu ditanggung akibat ketidaksiapannya menghadapi perubahan. Untuk memperoleh data dan informasi yang akurat, penelitian ini menggunakan teknik observasi dan wawancara langsung dengan manajemen perusahaan dan orang kunci departemen Teknologi Informasi. Dapat disimpulkan bahwa memperkuat infrastuktur teknologi informasi sama nilainya dengan memperkuat proses bisnis yang dibangun di atasnya, dan menambah nilai tambah bagi suatu perusahaan.
\end{abstract}

Kata kunci: infrastruktur teknologi informasi, fleksibilitas, proses bisnis 


\section{PENDAHULUAN}

PT XYZ menjadi perusahaan indukdari dua perusahaan tambang Batubara dengan lisensi ijin mulai tahun 2005 sampai dengan tahun 2035 dan 2036 berdasarkan Kontrak Karya Batubara (Coal Contract of Work "CCOW"). Konsesi masing-masing anak perusahaan berada di Indragiri, propinsi Riau dan Muara Bungo, Jambi. Induk perusahaan berpusat di Jakarta, sedangkan port berada di daerah Rengat.

Dalam rangka go public pada tahun 2013 dan masuk dalam jajaran 10 besar perusahaan Batubara di Indonesia, PT XYZ memerlukan konsistensi dalam memproduksi Batubara berkualitas tinggi dalam memenuhi kebutuhan pelanggan. Selain itu, PT XYZ perlu tetap bertahan dan peningkatan terhadap profitditengah pesaingan yang ada. Jumlah proyek yang semakin tinggi, pelanggan yang semakin luas. Sejumlah ekpansi site, dan sebagainya akan mempengaruhi meningkatnya kompleksitas proses dan biaya. Hal ini menuntut perusahaan untuk memiliki infrastruktur yang fleksibel dengan strategi bisnis, salah satunya infrastruktur teknologi informasi. Fleksibel dalam teori organisasi, stategi manajemen dan termasuk sistem informasi dapat diartikan sebagai kemampuannya dalam meresponi perubahan lingkungan (Lee \& Xia, 2003).

Pentingnya peningkatan kemampuan infrastruktur IT diakui menjadi semakin penting untuk kelangsungan hidup dan daya saing suatu organisasi (Broadbent et al. 1996; Chung et al. 2003). Infrastuktur IT perlu dikembangkan untuk memfasilitasi organisasi dalam berbagi data dan informasi serta sanggup mengintegrasikan lintas fungsi yang ada yang dihasilkan dari sistem aplikasi yang sama maupun berbeda (Darnton \&Giacolette, 1992).

Menurut Xia dan King (2004), infrastuktur IT menjadi pondasi yang kekuatannya akan dibagikan dan menentukan kekuatan sistem aplikasi yang dibangun di atasnya dan bisnis proses yang didukungnya. Byrd dan Turner (2000) mendefinisikan infrastuktur IT yang fleksibel sebagai kemampuan organisasi dalam mendukung berbagai jenis system informasi dan teknologi informasi. Fleksibilitas ini dapat dikarakteristikan dalam dimensi compatibility, connectivity, modularity dan flexible IT personel(Byrd \& Turner, 2000; Tallon \& Kreamer, 2003; et al., 2003; Ness, 2005; Chung et al., 2005).Kemampuan ini dapat dibangun secara lokal oleh Departemen IT internal, ataupun menggunakan fasilitas outsource eksternal (Weill \& Broadbent, 1994; PE International, 1995).

Tujuan penelitian ini untuk mengidentifikasi dan megevaluasi resiko terhadap infrastruktur IT dari PT XYZ yang ada saat ini serta rekomendasi perbaikan yang diperlukan dalam menjawab tantangan dan pengembangan strategi perusahaan.

\section{METODE}

Beberapa persiapan yang perlu dilakukan adalah dengan melengkapi pengetahuan tentang profil perusahaan yang akan dikaji dan mempersiapkan pertanyaan yang akan diajukan kepada Manajemen terkait strategi perusahaan dan kepala Departemen Information Technology terkait infrastruktur IT.

Beberapa fase yang dilalui dalam pencapaian penelitian ini, antara lain: (1) identifikasi permasalahan - dengan teknik wawancara bersama dengan Director dari perusahaan untuk mengungkap pencapaian dan strategi pengembangan perusahaan, menggali keinginan manajemen terhadap dukungan system dimasa mendatang, melakukan observasi terhadap system yang sedang dijalankan, skema dan kondisi intranet, internet dan mengidentifikasi kecukupan personil Departemen 
IT, serta mengindentifikasi keluhan yang sering muncul dan kekurangan system dan jaringan; (2) analisis infrastruktur IT dan potensi resiko - dari temuan yang ditemukan diverifikasi dari tahap 1 dilakukan analisis tingkat fleksibilitas infrastruktur IT berdasarkan perspektif compatibility, connectivity, modularity dan flexible IT personel berdasarkan masukan-masukan lewat brainstorming dan melakukan kajian literatur untuk analisis resiko; (3) rekomendasi solusi - membangun solusi yang akan direkomendasikan sebagai perencanaan strategi dari Departemen IT dan kemudian melakukan verifikasi terhadapnya.

Secara kesuluruhan, kerangka pikir penelitian dirancang dengan langkah-langkah sebagai berikut (Gambar 1).

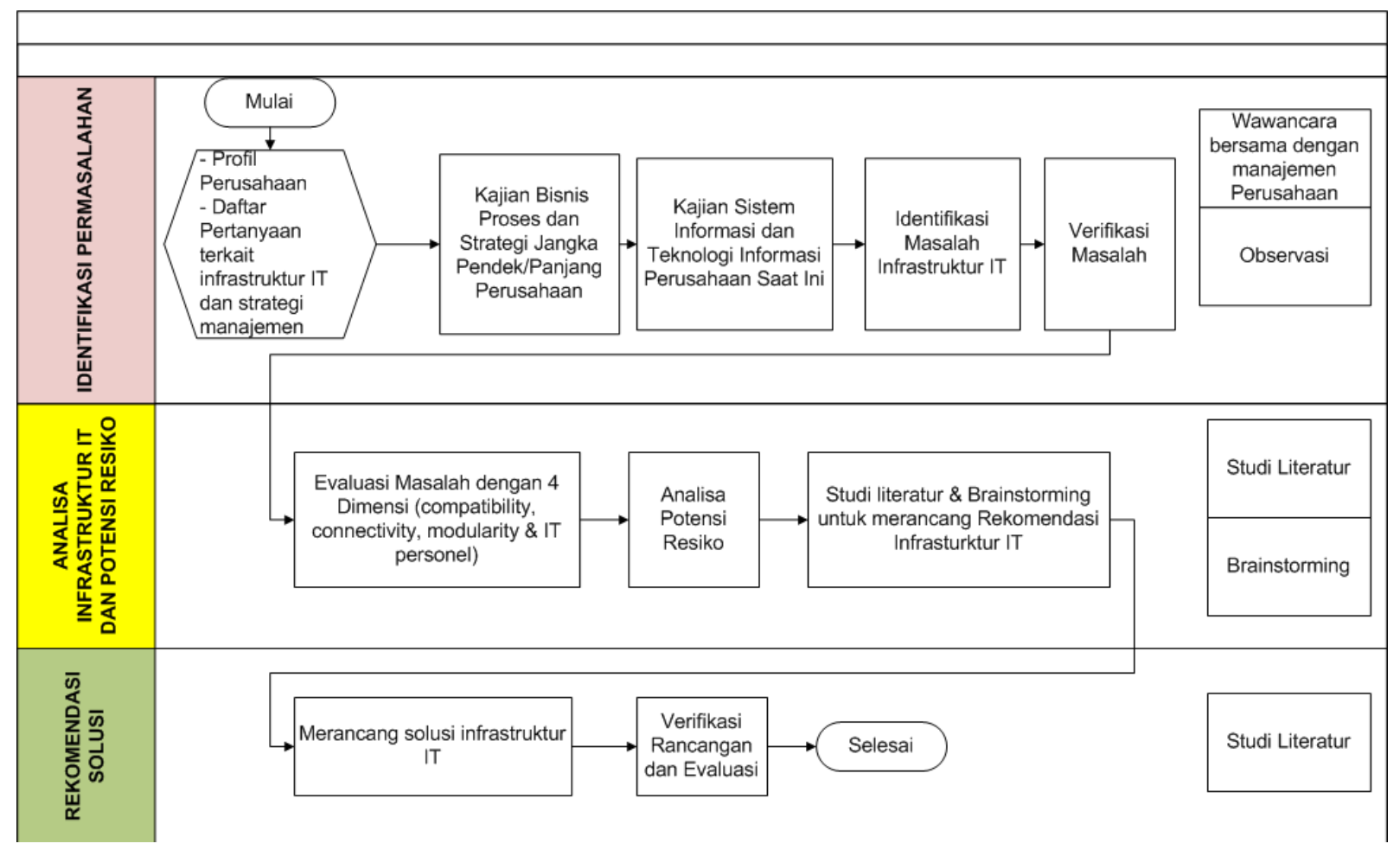

Gambar 1 Kerangka pikir penelitian

\section{HASIL DAN PEMBAHASAN}

Berdasarkan eksekutif interview bersama kepala Departemen TI, berikut ini gambaran arsitektur jaringan internet pada site, port dan perusahaan induk di PT XYZ (Gambar 2). site telah mendaftarkan tiga Telkom Speedy ADSL broadband up to $1 \mathrm{Mbps}$ untuk koneksi internet yang dikombinasikan kedalam satu koneksi menggunakan sebuah router. Internet koneksi di salah satu area (Rengat) untuk memberikan layanan untuk area tambang dan port di mana PT XYZ menyewa tempat untuk menaruh router dan modem. Koneksi internet dikirim dari kantor area tambang menggunakan radio alat mikrotik ke menara, dan kemudian dari kantor mengarahkan (routing) koneksi ke kantor yang ada di port menggunakan alat yang sama. Koneksi dibagi untuk 70 orang yang berada di kedua kantor tersebut. Koneksi internet secara umum digunakan untuk berkomunikasi dengan Perusahaan Induk melalui email yang di hosting secara eksternal di CBN. 


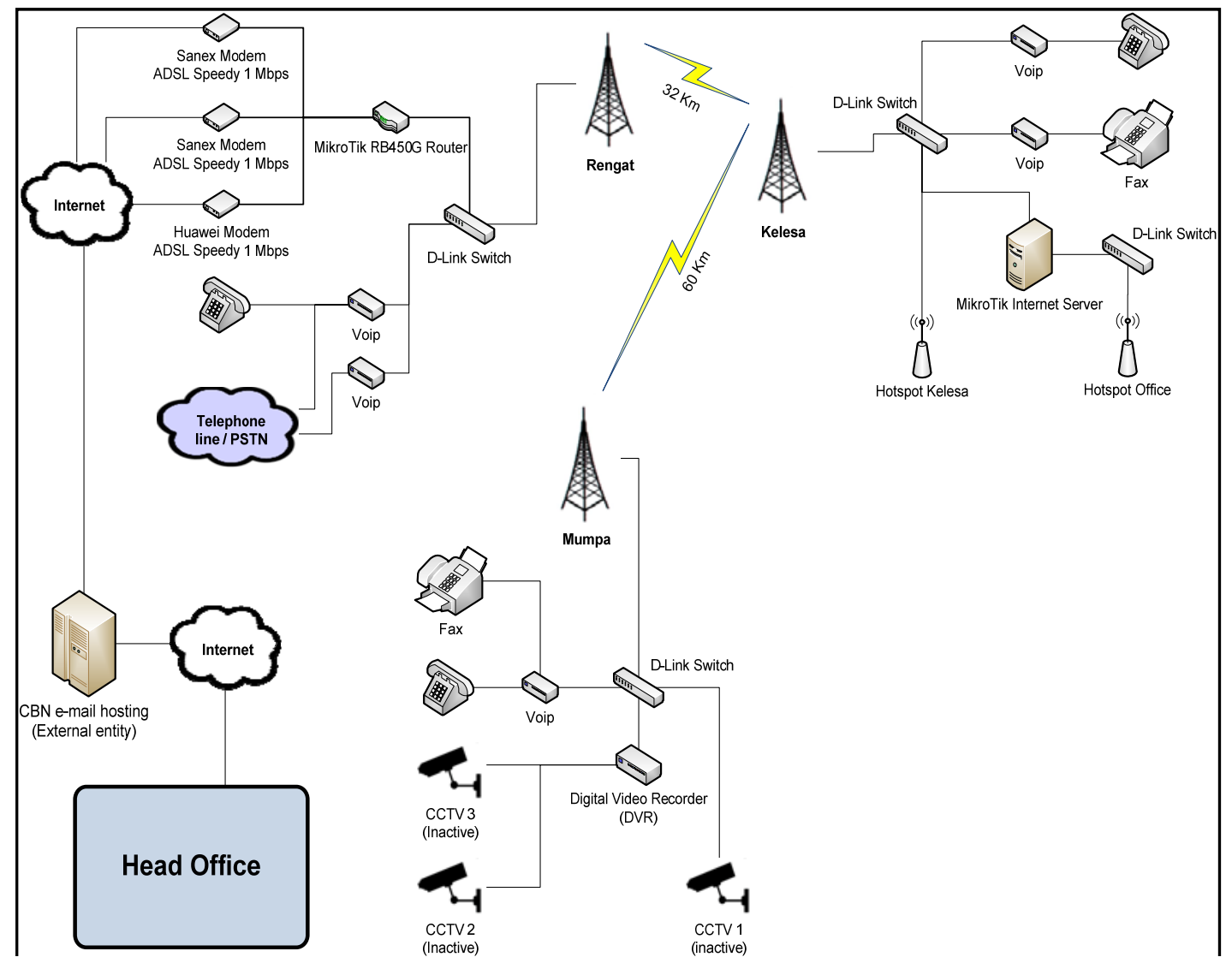

Gambar 2 Infrastruktur jaringan perusahaan induk dan site saat ini.

Berdasarkan wawancara dengan manajemen dalam hal ini Direktur PT XYZ berikut ini beberapa hal yang diinginkan manajemen terkait dengan infrastruktur dan system IT (Tabel 1).

Tabel 1 Dampak Rencana Pengembangan Perusahaan terhadap Teknologi Informasi

\begin{tabular}{|c|c|}
\hline $\begin{array}{c}\text { Rencana Pengembangan Manajemen dan } \\
\text { Dampaknya }\end{array}$ & Tuntutan Perubahan Teknologi Informasi \\
\hline $\begin{array}{l}\text { Strategi ekspansi perusahaan dengan mengakuisisi } \\
\text { perusahaan-perusahaan baru. } \\
\text { Dampak: } \\
\text { Akibat dari kondisi ini adalah di mana masing- } \\
\text { masing perusahaan akan membawa proses dan } \\
\text { system yang masing-masing yang saling berbeda } \\
\text { sehingga akan mempersulit }\end{array}$ & $\begin{array}{l}\text { (1). Mengembangkan system dan infrastruktur } \\
\text { yang multiplatform, dapat menjalankan } \\
\text { berbagai tipe aplikasi; } \\
\text { (2). Infrastruktur yang dibangun dengan } \\
\text { peralatan yang scalabledan durable, } \\
\text { sehingga meminimalisasi upgrading cost }\end{array}$ \\
\hline $\begin{array}{l}\text { Ekspansi site akan berkembang baik Sumatera } \\
\text { maupun Kalimantan. Jumlah karyawan dan } \\
\text { fungsi/departemen yang semakin beragam. } \\
\text { Dampak: } \\
\text { penambahan jumlah koneksi yang dibutuhkan } \\
\text { membutuhkan banyak biaya untuk pembangunan } \\
\text { jaringan untuk yang belum memiliki jaringan } \\
\text { sama sekali. }\end{array}$ & $\begin{array}{l}\text { (1). Standarisasi kebijakan dan prosedur IT; } \\
\text { (2). Penataan infrastruktur dan sistem aplikasi } \\
\text { yang dijalankan untuk keseluruhan group, } \\
\text { tidak hanya per-perusahaan sehingga dapat } \\
\text { menunjang integrasi dengan lebih baik; } \\
\text { (3). Performa koneksi yang cepat; } \\
\text { (4). Ekspansi Departemen IT }\end{array}$ \\
\hline $\begin{array}{l}\text { Sistem pelaporan keuangan yang mendukung dual } \\
\text { currency dan laporan konsolidasi }\end{array}$ & $\begin{array}{l}\text { (1). Membutuhkan otomatisasi laporan yang } \\
\text { mempercepat kesediaan data dan laporan }\end{array}$ \\
\hline
\end{tabular}




\begin{tabular}{|c|c|}
\hline $\begin{array}{l}\text { Dampak: } \\
\text { Sistem keuangan yang berbeda-beda, yang } \\
\text { memiliki struktur yang berbeda, menghasilkan } \\
\text { laporan yang berbeda. Sehingga saat ini } \\
\text { konsolidasi menjadi "painful area" }\end{array}$ & $\begin{array}{l}\text { yang dibutuhkan perusahaan; } \\
\text { (2). Sistem yang mendukung dual currency } \\
\text { report dan consolidation }\end{array}$ \\
\hline $\begin{array}{l}\text { IPO dan Corporate Branding } \\
\text { Tantangan : } \\
\text { Meciptakan corporate website yang baru yang } \\
\text { lebih menarik dan informative }\end{array}$ & Manajemen content website \\
\hline
\end{tabular}

Berdasarkan hasil observasi dan wawancara bersama dengan kepala Departemen Teknologi Informasi, dilakukan analisis permasalahan terhadap beberapa area infrastruktur IT baik di perusahaan induk maupun di site atau port untuk menguji tingkat compatibility, connectivity, modularity dan IT personel (Tabel 2).

Tabel 2 Area Analisis dan Dimensi Analisis Infrastruktur

\begin{tabular}{|c|c|c|c|c|}
\hline Area Analisis Infrastruktur IT & Compatibility & Connectivity & Modularity & $\begin{array}{c}\text { Flexible IT } \\
\text { Personnel }\end{array}$ \\
\hline Infrastruktur jaringan & & $\sqrt{ }$ & & \\
\hline Infrastruktur server & $\sqrt{ }$ & $\sqrt{ }$ & & \\
\hline $\begin{array}{l}\text { Infrastruktur sistem aplikasi dan } \\
\text { website korporat }\end{array}$ & $\sqrt{ }$ & $\sqrt{ }$ & $\sqrt{ }$ & \\
\hline Sistem email & & $\sqrt{ }$ & & \\
\hline Data storage management & & $\sqrt{ }$ & & \\
\hline File server management & & $\sqrt{ }$ & & \\
\hline IT organization & & & & $\sqrt{ }$ \\
\hline
\end{tabular}

Masing-masing area dibahas secara detail, dikaji permasalahannya serta potensi resiko yang akan muncul yang menghambat perusahaan tidak hanya dari sisi operasional tapi juga dalam mengeksekusi strategi perusahaan secara produktif dan efisien. Melalui kajian literatur, selanjutnya dilakukan analisis rekomendasi pemecahan masalah untuk mencegah, mengurangi atau menghentikan resiko maupun yang berpotensi menjadi resiko (Tabel 3).

Tabel 3 Analisis Resiko Permasalahan Infrastruktur IT dan Rekomendasi Perbaikannya

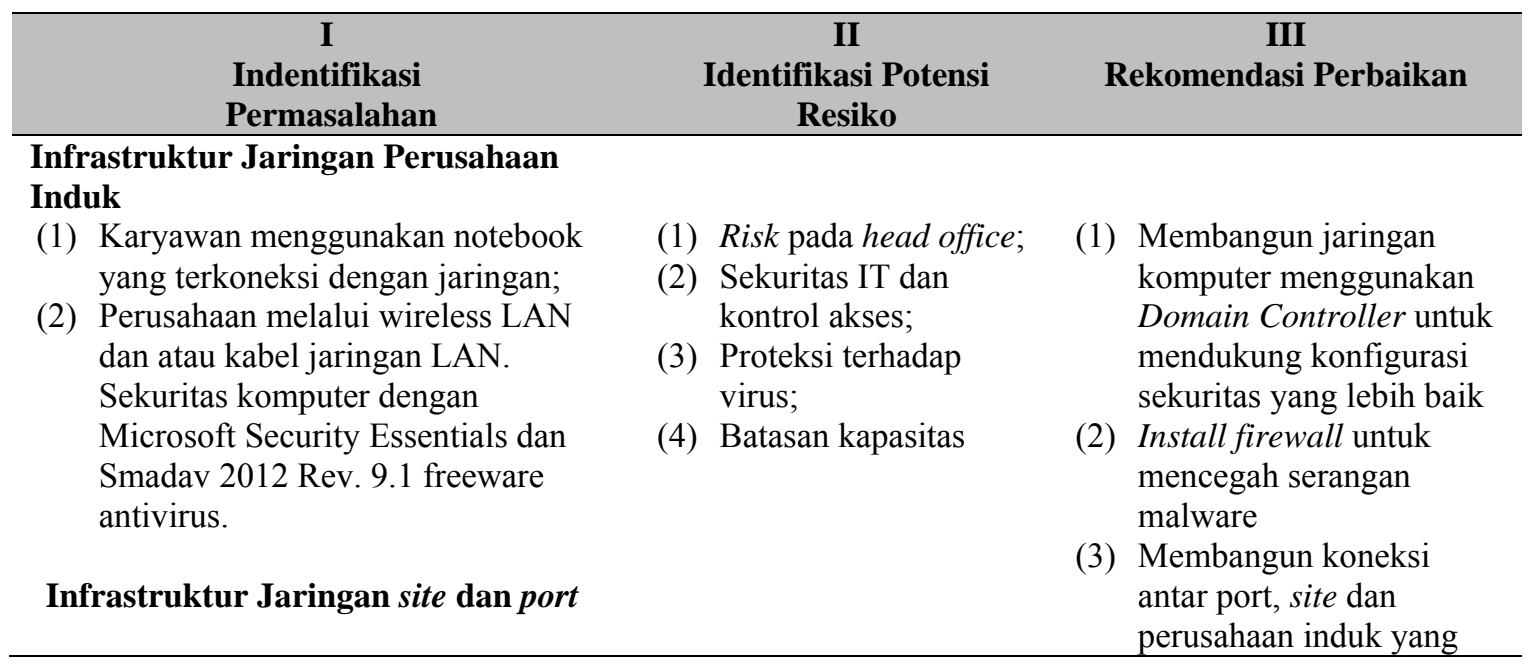




\begin{tabular}{|c|c|c|c|}
\hline & $\begin{array}{c}\text { I } \\
\text { Indentifikasi } \\
\text { Permasalahan }\end{array}$ & $\begin{array}{c}\text { II } \\
\begin{array}{c}\text { Identifikasi Potensi } \\
\text { Resiko }\end{array} \\
\end{array}$ & $\begin{array}{c}\text { III } \\
\text { Rekomendasi Perbaikan }\end{array}$ \\
\hline $\begin{array}{l}\text { (1) } \\
\text { (2) } \\
\text { (3) }\end{array}$ & $\begin{array}{l}\text { Komunikasi dari Perusahan Induk ke } \\
\text { site dan port menggunakan standard } \\
\text { koneksi internet tanpa VPN akses } \\
\text { yang aman; } \\
\text { Koneksi intertnet pada site dan port } \\
\text { menggunakan Telkom Speedy } \\
\text { dengan kecepatan 1Mbps untuk } \\
\text { masing-masing site dengan } \\
\text { pengguna sekitar } 70 \text { user. Setiap } \\
\text { penyewaan speedy sudah termasuk } \\
\text { Router dan Modem; } \\
\text { Manajemen bandwith dilakukan } \\
\text { dengan melakukan limitasi } \\
\text { penggunaan untuk setiap user, } \\
\text { pemblokiran situs yang tidak terkait } \\
\text { dengan pekerjaan yang berpotensi } \\
\text { memakan bandwith besar. }\end{array}$ & & $\begin{array}{l}\text { aman dengan Virtual } \\
\text { Private Network (VPN) } \\
\text { (4) Melakukan update } \\
\text { antivirus dengan yang } \\
\text { terbaru dan sudah } \\
\text { terpercaya untuk } \\
\text { menjamin kelangsungan } \\
\text { layanan antivirus yang } \\
\text { diberikan. }\end{array}$ \\
\hline
\end{tabular}

\section{Website Korporat}

Website korporat menyediakan informasi ke publik dan potensial investor. Saat ini belum ada IT personil yang melakukan maintenance dan memperbaharui isi website.
Reputasi dan pencitraan public
(1) Penugasan untuk Departemen IT yang memiliki kemampuan untuk melakukan pemeliharaan dan pembaharuan website;

(2) Membangun corporate website baru dengan konsep content management system untuk memudahkan fleksibilitas dalam mengatur isi website

\section{Sistem Email}

Hosting email pada Google Server untuk 500 akun email:

(1) Manajemen aktifasi dan non-aktifasi akun email belum diatur. Karena banyak email dari karyawan yang sudah tidak non-aktif atau sebaliknya karyawan aktif yang masih belum memiliki email

(2) Analisis penggunaan email yang belum dilakukan.
(1) Penyalahgunaan email oleh karyawan non-aktif

(2) Privasi dan pengaksesan data secara ilegal
(1) Bisnis proses aktifasi dan non aktifasi email, bekerjasama dengan Departemen Human Resources

(2) Penugasan staff IT untuk melakukan manajemen akun dan sekuritas email

(3) Menggunakan email server yang dikelola secara lokal sehingga dapat meningkatkan efisiensi tanpa mengurangi tingkat kehandalannya

\section{Data Storage}

(File Server) \& Management

Pada Perusahaan Induk: 


\begin{tabular}{|c|c|c|}
\hline $\begin{array}{c}\text { I } \\
\text { Indentifikasi } \\
\text { Permasalahan }\end{array}$ & $\begin{array}{c}\text { II } \\
\text { Identifikasi Potensi } \\
\text { Resiko }\end{array}$ & $\begin{array}{c}\text { III } \\
\text { Rekomendasi Perbaikan }\end{array}$ \\
\hline $\begin{array}{l}\text { (1) Terdapat } 4 \text { file server dengan rata-rata } \\
\text { 2GB RAM dan prosesor } 2.3 \text { Ghz yang } \\
\text { terhubung dalam LAN; } \\
\text { (2) Penyimpanan pada server masih } \\
\text { menyatukan aplikasi, database, dan } \\
\text { file sharing masing-masing } \\
\text { departemen; } \\
\text { (3) Karyawan dapat mengakses folder- } \\
\text { folder sharing dari departemen lainnya } \\
\text { Pada Area site: } \\
\text { (1) Belum ada sentralisasi penyimpanan; } \\
\text { (2) Business user banyak menggunakan } \\
\text { flash disk untuk melakukan transfer } \\
\text { data; } \\
\text { (3) Transfer data dari area site dan } \\
\text { peusahaan induk masih banyak } \\
\text { mengandalkan email yang terbatas } \\
\text { ukurannya. }\end{array}$ & $\begin{array}{l}\text { (1) IT security dan } \\
\text { kontrol akses } \\
\text { (2) Data backup dan } \\
\text { recovery }\end{array}$ & $\begin{array}{l}\text { (1) Membangun jaringan } \\
\text { yang aman dengan } \\
\text { Domain Controller untuk } \\
\text { mendukung konfigurasi } \\
\text { yang menjamin sekuritas } \\
\text { jaringan; } \\
\text { (2) Membangun cloud server } \\
\text { dan menyediakan folder } \\
\text { sharing untuk masing- } \\
\text { masing departemen dan } \\
\text { melakukan kontrol file } \\
\text { sharing dengan } \\
\text { konfigurasi hak akses dari } \\
\text { folder yang di share; } \\
\text { (3) Mengamankan file server } \\
\text { dengan langkah-langkah } \\
\text { keamanan fisik dan logis. }\end{array}$ \\
\hline $\begin{array}{l}\text { IT Organization } \\
\text { Pada perusahaan Induk } \\
\text { Hanya ada satu orang IT Support yang } \\
\text { dishare untuk bertanggung jawab dalam } \\
\text { trouble shooting di perusahaan induk. } \\
\text { Pada site } \\
\text { Dua orang IT Support di Kelesa } \\
\text { bertanggung jawab untuk user yang } \\
\text { berada di area tambang, port site, dan } \\
\text { memelihara jaringan dan peralatan IT di } \\
\text { Rengat. } \\
\text { Pada port } \\
\text { Satu karyawan yang baru direkrut di site } \\
\text { Mumpa. Bertanggung jawab untuk user } \\
\text { yang berada di port site. Dan juga } \\
\text { memegang system inventory bernama } \\
\text { InFlow Inventory untuk mengontrol } \\
\text { persediaan yang ada di port site. }\end{array}$ & $\begin{array}{l}\text { (1) Lemahnya kekuatan } \\
\text { personil IT; } \\
\text { (2) Lemahnya IT } \\
\text { Leadership dan IT } \\
\text { Governance }\end{array}$ & 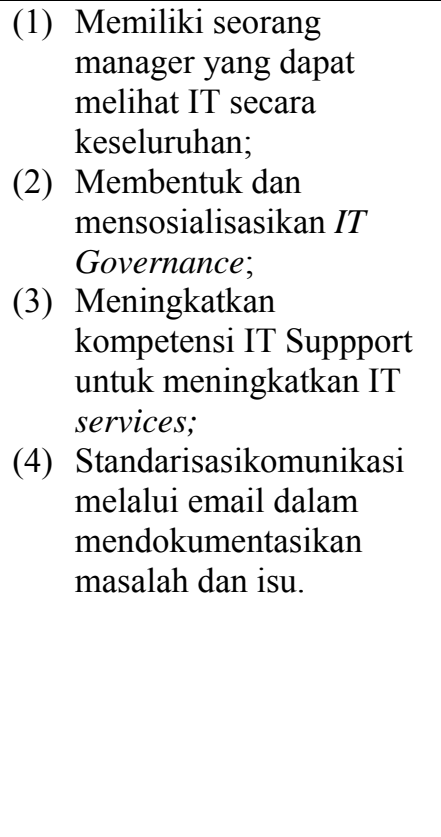 \\
\hline
\end{tabular}

Rekomendasi perbaikan dipertimbangkan dengan seksama untukmenjawab kebutuhan perusahaan terkait dengan empat dimensi fleksibilitas untuk periode waktu yang lama.

\section{PENUTUP}

Dapat disimpulkan bahwa kondisi infrastruktur IT pada PT XYZ cukup lemah dan banyak memberikan potensi resiko tingkat tinggi terhadap perkembangan perusahaan. Maka dari itu, rancangan infrastruktur IT perlu mendapatkan perbaikan, menunjang tingkat fleksibilitas yang tinggi sehingga dapat mencegah terjadinya masalah dalam pertumbuhan dan pengembangan perusahaan yang 
kerap dinamis, bahkan membantu perusahaan memperoleh keuntungan daripadanya. Merancang infrastruktur yang fleksibel memiliki sebuah nilai yang tinggi, yang seringkali tidak disadari oleh Perusahaan dan lebih mahal nilainya dibandingkan dengan nilai investasinya. Seiring dengan pertumbuhan teknologi informasi yang memiliki siklus hidup yang singkat, ditambah dengan perubahan bisnis yang melaju tidak dapat dihentikan, fleksibilitas infrastruktur IT perlu terus menerus perlu dengan disiplin dievaluasi dan ditingkatkan. Sehingga diharapkan IT dapat terus menerus mengimbangi kebutuhan dan menambahkan nilai dari setiap rantai proses yang dilakukan perusahaan.

\section{DAFTAR PUSTAKA}

Broadbent, M., Weill, P. O’Brien, T. \& Neo, B. S. (1996). Firm context and patters of It infrastructure capability. Proceedings of ICIS, Cleveland.

Byrd, T. A., \& Turner, D. E. (2000). Measuring the flexibility of information technology infrastructure: exploratory analysis of a construct. Journal of Management Information Systems, 17(1), 167 - 208.

Chung, S. C., Byrd, T. A., Lewis, B. R., \& Ford, F. N. (2005). An empirical study of the relationship between IT infrastructure flexibility, mass customization and business performance. The DATABASE for Advance in Information Systems, 36(3), 26 - 44.

Chung, S. K., Rainer, R. K., \& Lewis, B. R. (2003). The impact of information technology infrastructure flexibility on strategic alignment and applications implementations. Communications of the Association for Information Technology,11 (11).

Darnton, G., \& Giacoletto, S. (1992). Information and IT Infrastructures. Information in the Enterprise: It’s More Than Technology. Salem, Massachusetts: Digital Press, 273-294.

Lee, G. \& Xia, W. (2003). An Empirical Study on the Relationships between the Flexibility, Complexity and Performance of Information Systems Development Projects. Diakses dari http://misrc.umn.edu/workingpapers/fullPapers/2003/0301_020103.pdf.

Ness, L.R. (2005). Addressing the relationship among IT flexibility, strategic alignment and IT effectiveness: study overview and findings. Journal of Information technology management, 16 (2).

PE International. (1995). Justifying infrastructure investment. IT Management Programme Report. Egham, United Kingdom: Centre for Management Research, PE International.

Tallon, P. P \& Kreamer, K. L. (2003). Using Flexibility to Enhance the Alignment Between $\begin{array}{lc}\text { Information } & \text { Systems. } \\ \text { http://misrc.umn.edu/workshops/2003/spring/Tallon_042503.pdf. }\end{array}$

dari

Weill, P., \& Broadbent, M. (1994). Infrastructure goes industry specific. MIS, 35-39.

Xia, W. \& King, W. R. (2004). Antecedents of Organizational IT Infrastructure Capabilities. Diakses dari http://www.misrc.umn.edu/workshops/2004/fall/weidong.pdf. 